\title{
A cherry blossom moment in the history of heart valve replacement
}

\author{
Albert Starr, MD
}

Innovation usually occurs with the joining together of many elements across disciplines and scientific boundaries rather than the chance discovery of some new basic knowledge. The artificial valve was no exception and resulted from an intense and focused collaboration between me, then a very young heart surgeon, and Lowell Edwards, an elderly retired mechanical engineer (Figure 1).

It was 1958, and our clinical open-heart program in Portland, Oregon, was in its start-up phase. We had an active animal laboratory and could take on the project. Edwards wanted to develop an artificial heart, and I suggested one valve at a time, starting with the mitral. Individual aortic leaflets were already available, but mitral valve disease was a huge unsolved problem. We started with the pooling of our knowledge and developed an inventory of what we already knew. We did not have to really invent a valvewe needed only to find the best materials and the appropriate geometry. Only a few materials were available for human implantation: Dacron and Teflon as used in vascular grafts; Silicon rubber (Silastic; Dow Corning, Midland, Mich) as used in shunts for hydrocephalus; acrylic as used in the Hufnagel valve designed for the descending aorta; and stainless steel and Stellite 21 (Vitallium; Dentsply Austenal, York, Pa) used in orthopedics. For use in animals, the start-up questions were as follows:

- Could these materials be used in a valve structure as a durable implant?

- Could we implant the device using a suture technique?

- Are chordae tendineae necessary for left ventricular function?

- Would left ventricular function be impaired if a rigid device was connected to the annulus, preventing annular contraction?

- Would it be possible to achieve firm and lasting fixation in a moving heart?

- Would the valve be subject to thrombotic interference with function?

Later, to go from animal to human there would be other issues to address.

\footnotetext{
From Bioscience Research and Development, Providence Health and Services; and Oregon Health and Science University, Portland, Ore.

Address for reprints: Albert Starr, MD, 9155 SW Barnes Road, Suite 240, Portland, OR 97225-6625 (E-mail: astarr@ starrwood.com).

J Thorac Cardiovasc Surg 2010;140:1226-9

0022-5223/\$36.00

Copyright (c) 2010 by The American Association for Thoracic Surgery

doi:10.1016/j.jtcvs.2010.10.012
}

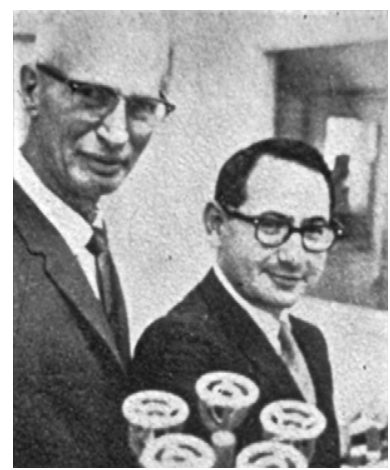

FIGURE 1. Lowell Edwards and Dr Albert Starr.

The first valves were Silastic leaflets mounted in a rigid Teflon O-ring and surrounded by a single-layer Dacron cloth sewing margin (Figure 2, $A$ ). We had a brief learning curve for the animal operation itself and then achieved predictable survival for a few days until thrombotic obstruction and partial dehiscence, or both, occurred (Figure 2, B). Left ventricular function was good, and we knew early on that a rigid device could function in place of a more flexible living structure. Partial valve dehiscence occurred frequently and was addressed by sewing ring redesign. With multiple layers of Teflon cloth acting as a cushion, we were able to achieve perfect coaptation. The zone of coaptation was made as large as possible to enhance stability and fibrous ingrowth (Figure 2, C). Now we had only the problem of early thrombosis. Clot formed at the zone of endocardial injury at the suture line and by direct extension involved the leaflets no matter how they were mounted (Figure 2,D).

The next logical step was to avoid leaflets entirely and use a moving, free-floating poppet as in a ball valve. This extended survival from 2 days to approximately 1 month. One dog, however, survived for many years. Now we could observe healthy animals with good cardiac function up to the time of their sudden death from thrombotic occlusion. Encouraged by our lone survivor, we kept up the implantation rate at 2 to 3 animals per week, but we were at an impasse. Finally, in February 1960, while running up the stairs to the research building at the University of Oregon Medical School (now Oregon Health \& Science University), my mind wandered, seeing the beautiful cherry blossoms around the entrance, and all of a sudden I had a eureka moment-why not cover the suture line with a retractable Silastic shield to prevent thrombus from reaching the valve orifice? It worked! We soon had a kennel full of happy dogs, one of whom licked the hand of the visiting chief of cardiology. I was planning to study the dogs over the next few 


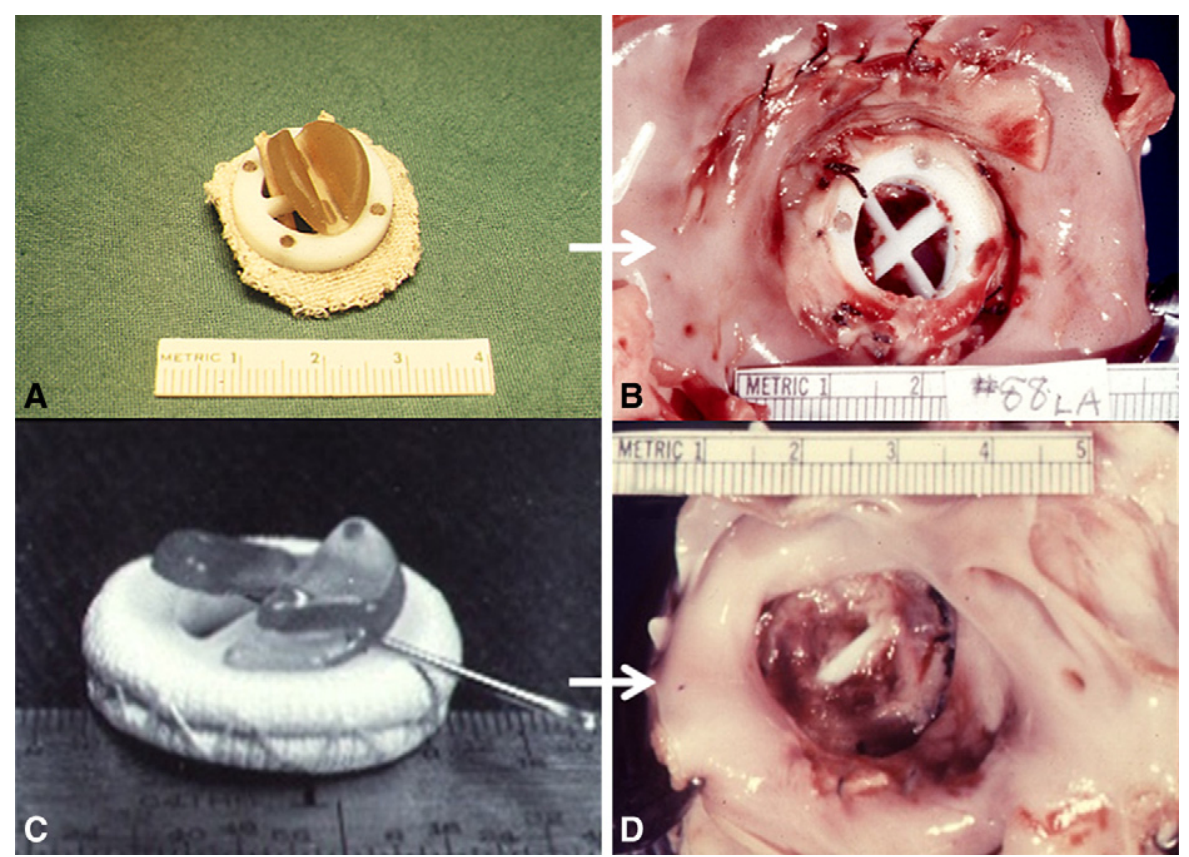

FIGURE 2. Leaflet type valves before implantations (A, C) and thrombosed after implant (B, D).

years looking for late complications, such as thromboembolism, hemolytic anemia, and infection. But both the chief of cardiology, Herbert Griswold, and the chief of surgery, Burt Dunphy, insisted that we proceed to human implantation.

To go from animal to human, we were now faced with a new set of problems. The Food and Drug Administration was not involved with implantable devices, and there were no guidelines. We were on our own to design a clinical trial.

Our first move was to develop an interdisciplinary team to select patients for operation and to provide continuous care postoperatively. The team included cardiologists, anesthesiologists, nephrologists, hematologists, neurologists, and even a psychiatrist.

Only high-risk patients with intractable congestive heart failure were selected for the initial implants. We had no intensive care unit and started one for this project. Most of the patients would require long-term ventilatory support, and without indwelling endotracheal tubes for long-term use we had to use tracheostomy and special volume-cycling respirators. We literally mobilized the whole medical school faculty for this project.

We had to choose an operative approach and tried left thoracotomy, right thoracotomy, and finally midline sternotomy.

There were ethical issues to address as well. Written informed consent was not at that time part of ordinary practice. We wrote our own. In addition, we committed to lifetime follow-up of the patients with sound statistical analysis. ${ }^{1}$ Edwards, who was making the valves by hand, would have to form a company and address liability issues.
The stage had to be set for continued refinement and testing of the valve for durability.

The big issue was the choice of valve for the first patient. Should it be the simple ball valve that achieved long-term survival in only 1 dog of more than 50 or the shielded valve that provided predictable long-term survival in $80 \%$ of the cases (Figure 3)? We did not make this decision by committee consensus. I grappled with it myself and decided on the simple device for the first implant. The thinking was this: If we started with the simple device and it worked, we would not have to use the more complicated valve. If it did not work, we could then go to the more complicated valve.

However, if we started with the more complicated valve and it worked, how would we know whether the simple valve might also have worked? So we started with the simple valve, and the shielded valve, which was so attractive in experimental animals and laid the ground work for our work in humans, was never implanted in a human.

The first patient was already in the hospital and in congestive failure after 2 previous attempts at reparative surgery. She was 33 years old and underwent operation on August 25, 1960.

Her left atrium was massively dilated, almost filling the right chest. We implanted the simple device as in our sole dog survivor. The operation was easier than in the dog, and she was returned to the anesthesia wakeup room, now converted to an intensive care unit, by mid afternoon. The chief of medicine listened to her valve. I watched his mustache quiver as he leaned down, stethoscope to the patient's chest. "Nice job, Al" was all he said. That evening, we sat 

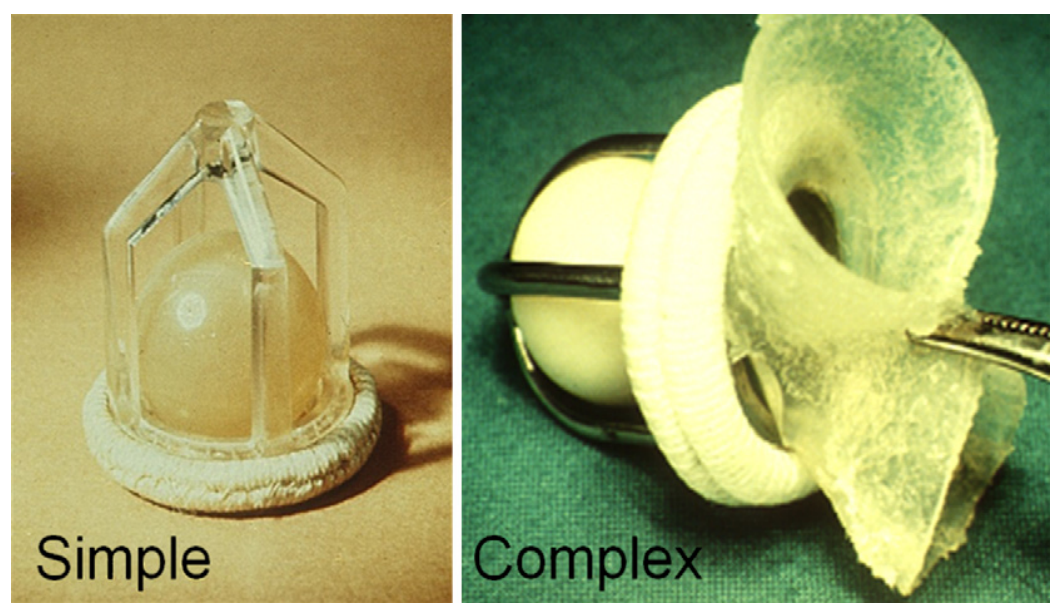

FIGURE 3. Original caged ball valve (left) and shielded ball valve (right).

her up for a portable chest x-ray. The x-ray showed an air fluid level in the right chest thought by the radiologist to be in the pleural space, which we thought was a small collection of blood and air outside the lung. Later that night, she expressed a desire to lie on her right side. While I was helping her, she gasped and died suddenly in my arm. Unfortunately, the air fluid level was inside the heart itself. The cause of death was massive air embolism. Pledging to myself that I would never let that happen again, I was able to sleep that night.

Less than a month later, on September 21, 1960, we operated on our second patient, a 52-year-old man. He also had 2 previous attempts for repair for calcified mitral stenosis.

He survived easily with only 1 complication — transient jaundice, cause unknown but possibly from anesthetic toxicity. We continued the series of implants with approximately 2 patients per month. Operative mortality decreased from approximately $50 \%$ in 1960 to less than $10 \%$ in 1965 (Figure 4). An early problem was prosthetic valve endocarditis. However, by reorchestrating the sterile technique in the operating room and treating both the patient and the team as potential staphylococcus carriers, we came close to eliminating early infection. Our first report was given to the American Surgical Association in the spring of 1961 and published in the Annals of Surgery. ${ }^{2}$ A similar presentation was given at the spring meeting of the American Association for Thoracic Surgery. There was enormous international interest, and we now had an obligation to run clinical trials at many other medical centers, with Edwards keeping close track of their results as well as our own.

With Edwards Laboratories (now Edwards Lifesciences, Irvine, CA) established in California in 1960, we were able to rapidly improve the device as we learned from our experience.
Accelerated fatigue tests demonstrated durability to beyond 40 years without prosthetic damage. All of the modifications of design took into account the lubricity of blood as measured by Edwards early in our animal experience. A major design constraint was to be certain that the force of ball contact with the cage would never exceed that allowed by blood as a lubricant. Red blood cell survival was diminished but not enough to cause hemolytic anemia unless there was a perivalvular leak. Thus, in a sense the prosthesis could injure red cells but not itself. A major goal of the various stages in development of the mitral prosthesis was to diminish the amount of metallic material exposed to the blood because thrombus on a metallic surface could break off and produce an embolic event. It took us 6 years with multiple sequential changes to arrive at the final design (Figure 5).

After our presentation at the American Association for Thoracic Surgery meeting, I visited Dwight Harken to watch an aortic valve replacement and realized that his device could be improved dramatically with good engineering support. We began a crash program to modify the

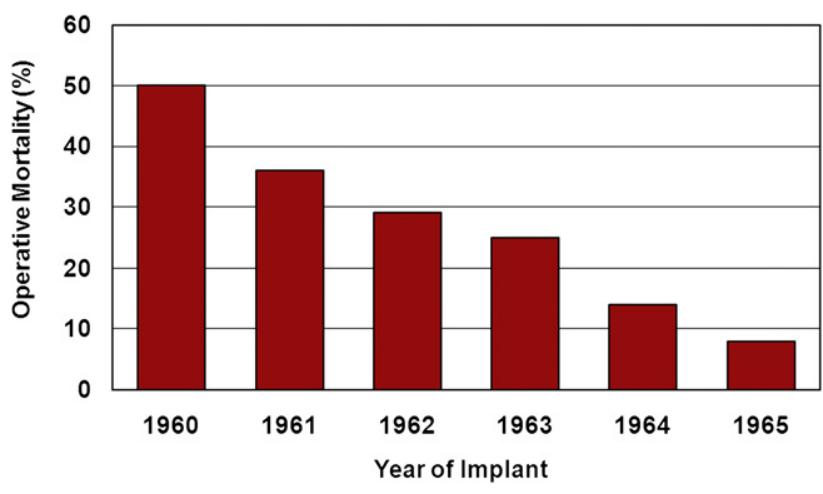

FIGURE 4. Operative mortality by implant year for mitral valves. 


\section{ENGINEERING DEVELOPMENT CHARTS}

STARR-EDWARDS MITRAL VALVE. SEPTEMBER 1960 - MARCH 1966

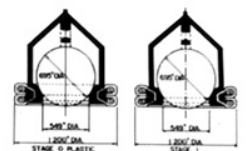

CLINICAL EXPERIMENTAL
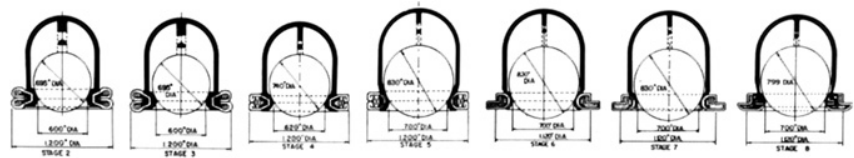

STANDARD PRODUCTION
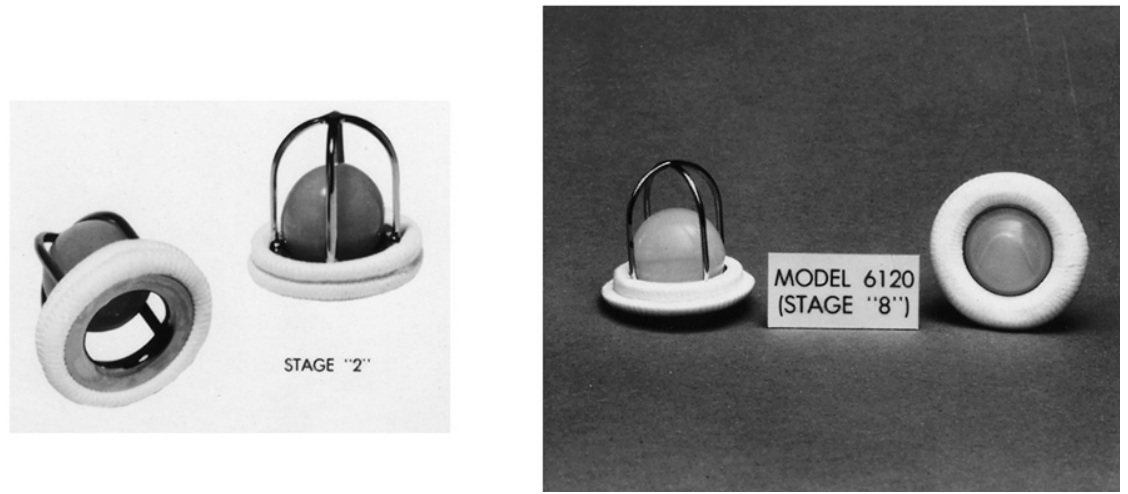

FIGURE 5. Evolution of the Starr-Edwards mitral valve from 1960 to 1966. mitral design to function as an aortic prosthesis. The sewing ring configuration was extended downstream from the prosthesis and was more suitable for the aortic annulus. The number of struts was reduced to 3 so they could be lined up with the commissures of the natural valve. This helped to limit the possibility of an embolic event from thrombus on a strut entering the coronary ostia that are far from the valve commissures. It also allowed the poppet to be removed during implantation to provide better vision of the site and reinserted after the device was sewn into place. Our first clinical experience with the aortic valve was in September $1961 .^{3}$

Once we had the aortic valve, multiple valve replacements became possible. Modern cardioplegia was not yet available, and we used pure cold blood intermittently per- fused through the coronary ostia with handheld cannula. We performed our first triple valve replacement in 1963 and showed the movie at the meeting of the American Association for Thoracic Surgery that year, to a standing ovation. ${ }^{4}$ This was just the beginning, and the rest is interesting and well documented in the literature.

\section{References}

1. Gao G, Wu Y, Grunkemeier GL, Furnary AP, Starr A. Forty-year survival with the Starr-Edwards heart valve prosthesis. J Heart Valve Dis. 2004;13:91-6.

2. Starr A, Edwards ML. Mitral replacement: clinical experience with a ball-valve prosthesis. Ann Surg. 1961;154:726-40.

3. Starr A, Edwards ML, McCord CW, Griswold HE. Aortic replacement: clinical experience with a semirigid ball-valve prosthesis. Circulation. 1963;27: 779-83.

4. Starr A, McCord CW, Wood J, Herr R, Edwards ML. Surgery for multiple valve disease. Ann Surg. 1964;160:596-613. 